\title{
Use Semi-Structured Discussion in Health Economics Seminars
}

\author{
Peng Zhou ${ }^{1}$, Cardiff University
}

\begin{abstract}
This article applies the semi-structured discussion approach to organising seminars in higher education using an undergraduate Health Economics module as a case study. It provides the theoretical rationale by re-investigating the different roles of lectures and seminars in learning and teaching. Evidence shows that it significantly improves the students' engagement and active thinking in a social learning environment, because a dialectic discussion involving both students and tutors results in a deeper understanding of welfarism and alternative value system, which are the fundamental principles underlying people's decision-making related to trade-offs between outcome efficiency and procedural fairness. Therefore, this approach is believed to improve the long-term holistic development of students' values and attitudes towards social, economic, environmental and cultural matters.
\end{abstract}

Key Words: Semi-Structured Discussion, Social Learning, Efficiency and Fairness, Health Economics

${ }^{1}$ D47, Aberconway Building, Cardiff University. Email: zhoup1@ @ardiff.ac.uk 


\section{Introduction}

A heated discussion on the clash between the traditional and interactive teaching approaches has recently been provoked by a BBC documentary ${ }^{2}$ at the pre-university level in the UK, but the same question applies to the university level teaching (Hanushek, 2011). Arguably, there is no universally best teaching approach for all subjects at all levels in all scenarios (Allen et al, 2014), therefore this paper aims to focus on the teaching approach to the undergraduatelevel economics seminar, with an experimental teaching intervention in a level 7 (year 3) undergraduate health economics module. An important reason for choosing this module as the case study of this action research is that in this module we have introduced and reflected on alternative value systems which form the fundamental criteria underlying the students' decision-making in the future, especially on the matters involving trade-offs between outcome efficiency and procedural fairness (Hadsell, 2005; Chalton, 2006). Examples include but not limited to healthcare funding, environment protection, and poverty mitigation. The feedback from the students suggests that a good balance between effective ness and efficiency in the learning and teaching is gained under the semi-structured discussions, compared to the unstructured students-led or the structured lecturer-led fashion.

The traditional approach to teaching seminars in economics is "chalk and talk", which has been pervasive for decades (Siegfried and Fels, 1979; Bach and Kelley, 1984; Becker and Watts, 1996; Becker and Watts, 2001). One main reason is that modern economics heavily relies on mathematics and logical arguments. A typical economics seminar in this old fashion is more or less carried out like the following: tutor gives the students exercises beforehand, tutor goes through each question in details, students take notes of the answer and this is it. (Marmah, 2014) The advantage of this traditional approach is that it saves the students' time to obtain the standard answers. This is an approach with high efficiency measured by inputoutput ratio, since tutor leads the seminars and many exercises can be done within a short seminar. However, one obvious drawback of this approach is that students do not actively internalise the concepts, methods and techniques, because the structured seminar cannot accommodate each participant's learning need. Even if some tutors do ask questions now and then to promote student engagement, these questions asked are still planned ex ante. Seemingly, the tutors are doing the exercises with the students, but it is effectively the tutor who is actually practicing. In other words, due to the lack of effective interaction between the tutor and students, the role of seminar does not complement that of lectures. Fortunately, after the implementation of the QAA and NSS evaluation system in the UK, very few lecturers are still using the traditional structured approach in organising seminars today.

The fundamental purpose of learning and teaching at the university level is not memorising some "correct" answers for exams, but to accumulate the students' transferrable skills and

${ }^{2}$ BBC Two, "Are our kids tough enough? Chinese school." 
employability (Sloman and Mitchell, 2016). Even in the courses with heavy technicalities such as economics and mathematics, there has been a trend to apply student-led discussions in the seminars. It is believed to be able to encourage a social learning environment and be more tailored to the students' personal learning need. Nevertheless, the key concern is that students with weak understanding of the basic analysis techniques and threshold concepts may digress too far from the questions at hand (Cousin, 2006). And at the end of the seminar, the group discussion becomes group conversations, resulting a low learning efficiency. Therefore, the pure unstructured discussion, at the other end of the spectrum of teaching approach, may not be the best alternative to the traditional method in the economics context.

To resolve the balance of the efficiency and effectiveness in learning and teaching, it is essen tial to distinguish between the roles of lecture and seminar, especially for scientific subjects like economics. It is not likely to respond to each student's learning need in lecture, because of the big class sizes which are easily go over one hundred. As a nature of economics, the analytical framework and techniques have to be clearly lectured in a more structured fashion during the lectures. As a complementary part, seminars are designed to help students to internalise the concepts and techniques covered in lectures through practices, applications and discussions. Therefore, a seminar is supposed not to be another lecture. Nevertheless, unlike subjects like arts and philosophy in which seminars can be totally unstructured and there are usually no correct answers at all, a majority of economic hypotheses are falsifiable by facts and logic. Some structural starting point in the discussion is necessary. Although the discussion approach is not at all new in the literature nor in practice of teaching economics. The key contribution of this paper is to obtain the best balance in the structureness, or equivalently the unstructureness, of the discussion in a very specific context.

To summarise, the basic idea of semi-structured discussion approach is to promote students' engagement and reflect their own learning needs through discussion within a certain structure (Hansen, 1983). It is different from the traditional structured teaching approach which plans the problem sets and illustration of the answers beforehand, and different from the unstructured discussion where tutor only gives a topic without specific problem sets or answers. In semistructured discussion, tutor only plans the problem sets, without giving out the answer directly, nor the procedure of obtaining the answer. Students initiate the problem solving, and everyone can contribute to the discussion. Tutor's role is not to guide the students when they have no clue where to go, to intervene when they go too far away, and to summarise the key points when they conclude. Hence, the tutor's role is more like a participant rather than a leader.

\section{Application to Health Economics Teaching}

The semi-structured discussion is conducted in a year 3 undergraduate module, Health Economics. In the lecture, the three theories of economic evaluation in health care market are 
covered in a structured teaching fashion: Welfarism, Non-Welfarism and Extra-Welfarism. The most difficult part of distinguishing these theories is to understand the principles underlying these theories: Consequentialism and Fundamentalism.

To help students understand these key concepts, some exercises are designed for the students to understand these concepts by application. By actually using the principles in different scenarios, students will realise they may shift between different principles in different cases. Tutor points the difference out explicitly, and the participants' understanding will be improved via such active and interactive discussions.

The tutor first introduces a very simple scenario, in which students are required to make decisions according to their own values and belief.

[Scenario 1] A Driver's Dilemma

A train driver is passing a rail diversion with two directions, left and right. Due to some improper security management, there is one worker still working on the left diversion and four workers on the right diversion. No worker is aware of the coming train. Let's assume it is too late to stop the train. Now the driver has to make a decision to either run over one or four workers. If you are the driver, which direction will you choose and why?

Given the simple setup of the problem, students are actively participating in the discussion and come to a conclusion to turn the train to the left diversion to minimise the social welfare loss, or equivalently, to maximise the social welfare. They get an initial understanding of Consequentialism of Welfarism, which evaluates a system based on the outcome of the social welfare. Then, the tutor introduces a similar scenario with a subtle amendment.

\section{[Scenario 2] A Passenger's Dilemma}

A train is going to run over four workers in a one-way rail, but now both the four workers and the train driver are not aware of this dangerous situation. Instead, you and another man on the bridge over the railway see this coming disaster. You now have two options: (i) watch the disaster happening (with four workers die); or (ii) push the man next to you down to the railway between the four workers and the train to stop the train. The first option's consequence is to watch four people die, while the second option's consequence is to save the four people by killing one innocent person. Assume you will not be punished due to killing the person, which option will you choose and why?

This new scenario is a bit different from scenario 1, but the consequence is actually the same, i.e. either one person dies or four people die. Now the students have different opinions in discussion. Some students support option (ii) for the same reason as scenario 1, because as a "social planner", they try to maximise the social welfare. Killing one innocent person is better than 
killing four innocent people. However, some other students regard "killing to save" itself as a wrong thing so would not do it even it brings out a better outcome.

Now the tutor guides the direction of the discussion, what is the difference between the two scenarios? What makes you make different decisions? After some interactive communication, the tutor summarises the key difference of the two decision-makings: the first scenario does not involve how to realise some consequence, while the second scenario does. Therefore, if you choose to kill one instead of four in the first scenario, then it means you follow the Consequentialism principle. If you choose to kill the passenger to save the four in the second scenario, then you are Consequentialist and use Welfarism, because you make decision only according to the outcome or consequence. In other words, you believe that the ends justify the means. If you choose not to kill the passenger to save the four in the second scenario, then you follow Fundamentalist principle and use Non-Welfarism. You believe that the principles of ethics per se have fundamental value, not just the consequence.

Up to now, the students should be able to distinguish between Consequentialism and Fundamentalism, as well as between Welfarism and Non-Welfarism. To make their understanding consolidated, the tutor gives another real scenario.

\section{[Scenario 3] A Real Story}

A British ship sunk in the middle of Atlantic in the mid-16 ${ }^{\text {th }}$ century. A life boat saved five people: a priest, a lawyer, a journalist, a traveller and a 7-year old boy who was an orphan. The boy was seriously sick when he was saved by the life boat. In the first week, nothing happened. However, in the following week, two things happened. First, food and water ran out. Second, the boy's condition deteriorated. No one would survive another day if they did nothing. In this case, the four adults (i.e. the priest, the lawyer, the journalist and the traveller) made a decision: kill the dying boy, ate his flesh and drunk his blood. After another two weeks, the life boat was saved. The priest told the public their story, and the four adults were sent to court. If you are one of the jury members, will you convict them guilty?

This real story makes the students think more seriously, because they are now assigned a role in the reality. Discussion is carried out in a more serious atmosphere, since students have already understood the distinction of the two principles. They are now clear about their stances and principles, so they know what they are arguing for and against. The discussion ends up with a vote, just like in the realistic court. The majority of the class/jury vote for guilty, which is consistent with the reality. The four adults were convicted guilty for murder. Following that, the tutor raises some further questions for the students to discuss after the seminar, such as "what if the boy was already dead," "what if the boy volunteered to be killed," and "what if the four adults asked the boy for consensus before they killed him?" 
The tutor can then summarise the distinction between Consequentialism and Fundamentalism, which leads to the distinction between Welfarism and Non-Welfarism. Based on that, the tutor can interpret the Extra-Welfarism as a weighted average between Welfarism and NonWelfarism. This will then finish the seminar.

\section{Feedback and Evaluation}

The response rate is $80 \%$. The other two students were absent for that lecture. The questionnaire asks the students 5 multiple choice questions.

(i) This teaching intervention increases your interest in the topic.

(ii) This teaching intervention helps you understand the topic better.

(iii) This teaching intervention enables you to apply the theory to practice better.

(iv) This teaching intervention is better than the conventional way of teaching.

(v) You expect to have more of this form of teaching in the future.

Students are asked to choose between "strongly agree", "agree", "not agree" and "strongly not agree". The "neutral" option is intentionally omitted to avoid tick-and-go in filling questionnaires. Surprisingly, none of them chose "disagree" or "strongly disagree". This may be because the students are reluctant to discourage the lecturer's effort. Taking this into account, "strongly agree" is treated as positive, "agree" is treated as neutral, and any other choices are treated as negative. The feedback results are shown in Table $\mathbf{1}$.

Table 1 Feedback Results

\begin{tabular}{cccc}
\hline Question & "Strongly Agree" & "Agree" & Positive Response Rate \\
\hline (i) & 14 & 14 & $50 \%$ \\
(ii) & 15 & 13 & $63 \%$ \\
(iii) & 12 & 16 & $25 \%$ \\
(iv) & 15 & 13 & $63 \%$ \\
(v) & 14 & 14 & $50 \%$ \\
\hline
\end{tabular}

It is encouraging to see that the semi-structured discussion teaching intervention received positive feedback for most of the aspects, even at the harshest interpretation of their responses. Based on the feedbacks, they not only gained a better understanding by actively participate in the discussion, but also interactively contributed a lot to the rest of the class. This procedure promotes social learning and student engagement, which effectively help them internalise the concepts and theories into their own knowledge system.

The positive response to question (iii) is a bit low, maybe because the discussion focused too 
much on the understanding of the concept, rather than application of the concept. This indicates the inefficiency problem of discussion. Given the limited time, the more discussion is made, the less exercises can be done.

\section{Conclusion}

This article summarises and applies the semi-structured discussion approach in organising an economics seminar. It is different from traditional structured seminar, in the sense that the journey of getting the answers is not predetermined. It is also different from unstructured seminar, because some specific questions are planned beforehand. The tutor's role is not to lead the seminar, but to guide the discussion in the right direction.

A teaching intervention based on semi-structured discussion is applied to a year 3 economics seminar. Students are actively participating in and contributing to the discussion. With the help from the tutor, students gained more and deeper understanding of the concepts and theories from the active and interactive discussion. The feedback shows significant support to this form of discussion in economics seminars.

One limitation of the semi-structured discussion is that it still faces a tradeoff between effectiveness and efficiency. Discussion tends to take longer time than the traditional teaching approach. It might constrain the number of exercises and the scopes of seminars. Therefore, tutor must find a balance point between the depth and the width of contents covered in seminars.

\section{Reference}

ALLEN, R., BELFIELD, C., GREAVES, E., SHARP, C. \& WALKER, M. 2014. The costs and benefits of different initial teacher training routes. The Institute for Fiscal Studies.

BACH, G. \& KELLEY, A. 1984. Improving the teaching of economics: achievements and aspirations. American Economic Review, 74, 12-18.

Becker WE and Watts M. (1996) Chalk and Talk: A National Survey on Teaching Undergraduate Economics. The American Economic Review 86: 448-453.

Becker WE and Watts M. (2001) Teaching Economics at the Start of the 21st Century: Still Chalk-and-Talk. The American Economic Review 91: 446-451.

CHALTON, B. 2006. Lectures are an effective teaching method because they exploit human evolved 'human nature' to improve learning. Medical Hypothesis, 67, 1261-1265. 
COUSIN, G. 2006. An Introduction to Threshold Concepts. Planet, 17, 4-5.

Hansen WL. (1983) Improving Classroom Discussion in Economics Courses. The Journal of Economic Education 14: 40-49.

HADSELL, L. 2005. Exploring Values in the Classroom: Three Exercises for Introductory Economics. The American Economist, 49, 51-59.

HANUSHEK, E. 2011. The economic value of higher teacher quality. Economics of Education Review, 30, 466-479.

MARMAH, A. 2014. Students' Perception about the Lecture as a Method of Teaching in Tertiary Institutions, Views of Students from College of Technology Education. International Journal of Education and Research, 2, 601-612.

SIEGFRIED, J. \& FELS, R. 1979. Research on Teaching College Economics: A Survey. Journal of Economic Literature, 17, 923-969.

SLOMAN, J. \& MITCHELL, C. 2016. Lectures. Economics Network. 